\title{
MULTICULTURALISMO NA EDUCAÇÃO INFANTIL: MOTIVO DE OPORTUNIDADE OU OBSTÁCULO NA FORMAÇÃO DAS CRIANÇAS?
}

\section{ARTIGO ORIGINAL}

TORRES, Valmir Rogério ${ }^{1}$

TORRES, Valmir Rogério. Multiculturalismo na educação infantil: motivo de oportunidade ou obstáculo na formação das crianças? Revista Científica Multidisciplinar Núcleo do Conhecimento. Ano. 07, Ed. 01, Vol. 01, pp. 18-29. Janeiro de 2022. ISSN: 2448-0959, Link de acesso: https://www.nucleodoconhecimento.com.br/educacao/multiculturalismo-naeducacao, DOI: 10.32749/nucleodoconhecimento.com.br/educacao/multiculturalismo-na-educacao

\section{RESUMO}

$\mathrm{Na}$ sociedade atual, o convívio entre as diferentes culturas pode ser desencadeador de conflitos e gerador de violências, proporcionados pela intolerância e a necessidade de prevalecer as ideologias das culturas consideradas dominantes. Estes conflitos presentes nas relações se estendem para o ambiente escolar, fazendo com que as instituições tenham que lidar com eles, de maneira adequada, transformando-os em oportunidades de aprendizagem. A etapa da educação infantil oportuniza a possibilidade de trabalhar de maneira efetiva, através do lúdico, as questões que envolvem a diversidade, promovendo ações de tolerância, de harmonia e compreensão. Desta forma, este trabalho tem o objetivo de verificar através da literatura se o multiculturalismo presente nas escolas de educação infantil, representa uma oportunidade ou um obstáculo para a aprendizagem. Logo,

\footnotetext{
${ }^{1}$ Graduado em matemática e Pedagogia. Especialista em Gestão Educacional, Gestão de currículos para professores coordenadores, MBA em Gestão Empreendedora-Educação, Mídias na Educação, Neurolinguística. Mestrando - Programa de Pós-Graduação em Educação em Ciências e Matemática.
}

RC: 104601

Disponível em:

https://www.nucleodoconhecimento.com.br/educacao/multiculturalismo-na-educacao 
responderemos se as diversidades de hábitos, pensamentos e ações proporcionam possibilidades de aprendizagens que podem resultar em transformações sociais ou obstáculos no convívio em sociedade, desde os momentos iniciais deste convívio. A metodologia utilizada se remeterá à discussão de documentos oficiais e artigos, que buscam analisar o multiculturalismo na educação infantil e suas implicações na sociedade e na formação de sujeitos capazes de superar os preconceitos e discriminações. Concluímos que para o multiculturalismo representar uma oportunidade de aprendizagem na educação infantil, é necessário que as crianças compreendam a importância de se colocar no lugar do outro e percebam que as pessoas são diferentes, e independentemente disso, todas devem ser acolhidas e respeitadas. O professor deve assumir seu papel de mediador, aproveitando os momentos de conflitos para levar as crianças a vivenciarem sentimentos de solidariedade, tolerância, respeito, acolhimento e harmonia.

Palavras-chave: Multiculturalismo, Educação Infantil, Formação da criança.

\section{INTRODUÇÃO}

O mundo passa por constantes mudanças causadas por uma globalização neoliberal excludente, a partir do momento em que estas mudanças adotam a existência de uma sociedade monocultural.

No entanto, as sociedades hoje vêm clamando para que todas as vozes sejam ouvidas, para que se sintam respeitadas em suas individualidades e para que a justiça social prevaleça em um mundo marcado por uma cultura dominante.

O Relatório de Desenvolvimento Humano 2004, do Programa das Nações Unidas para o Desenvolvimento (PNUD), com o título "Liberdade cultural num mundo diversificado", destaca que:

Em todo o mundo as pessoas são mais afirmativas para exigir respeito pela sua identidade cultural. Muitas vezes, o que exigem é justiça social e mais voz política. Mas não é tudo. Também exigem reconhecimento e respeito... E importam-se em saber se eles e os filhos viverão em uma sociedade 
diversificada ou numa sociedade em que se espera que todas as pessoas se conformem com uma única cultura dominante. (PNUD, 2004, p. 22)

No Brasil, esta realidade é igualmente identificada, pois podemos notar facilmente as ações que envolvem os preconceitos e discriminações embarcadas por décadas em nossa sociedade e que até hoje prevalecem, causando conflitos profundos e capazes de marginalizar parcelas minoritárias da sociedade.

Tornam-se cada vez mais frequentes, notícias de violências das mais diversas formas que envolvem discriminações raciais, de sexualidade, de condições financeiras e sociais, entre outras. Tais violências são, em alguns momentos, apresentadas de forma aparente, sem que estas atitudes gerem desconfortos ou sejam causas de constrangimentos por quem as pratica.

De acordo com Barbosa (2014):

A diversidade cultural brasileira se deu pelo processo de miscigenação entre brancos, índios e negros e foi marcada por uma série de crenças, hábitos, costumes e conceitos contraditórios, alimentando, assim, uma discussão permanente a respeito dos direitos e deveres dos seres humanos, principalmente no combate aos preconceitos remanescentes e oriundos dessa relação que perdurou por séculos, trazendo sérias consequências a uma imensa população de oprimidos, incluindo negros, índios, pobres, portadores de algum tipo de deficiência, relações e diferenças sexuais, doenças crônicas, dentre outras formas de relações consideradas por boa parte da sociedade algo fora da normalidade e, por esse motivo, não aceitáveis.(BARBOSA, 2014, p. 3).

Considerando esta realidade, percebemos a necessidade em se pensar não só nos direitos individuais, mas também nos direitos coletivos, àqueles que serão capazes de proporcionar uma mudança na sociedade a tal ponto de garantir não somente a justiça social, mas através dela concretizar uma transformação social.

É importante que este processo de mudança aconteça desde cedo na vida dos indivíduos, por isso a necessidade de pensar sobre o multiculturalismo e os direitos humanos na educação infantil. Este artigo busca responder: as diversidades de hábitos, pensamentos e ações proporcionam possibilidades de aprendizagens que 
podem resultar em transformações sociais ou obstáculos no convívio em sociedade, desde os momentos iniciais deste convívio?

Desta forma, o objetivo geral deste trabalho é verificar se o multiculturalismo presente nas escolas de educação infantil representa uma oportunidade ou um obstáculo para a aprendizagem.

Os objetivos específicos são os de analisar, através de documentos oficiais voltados para a educação infantil, como as questões que envolvem a diversidade são tratadas no ambiente escolar. Refletir sobre o papel da escola diante das diversidades existentes na educação infantil, para que esta cumpra com seu objetivo de formar cidadãos. Verificar o papel do educador no processo de tratar os conflitos presentes na escola de educação infantil, visando fazer destes momentos, oportunidades de aprendizagens.

Para tanto, faremos uma discussão de documentos oficiais, que buscam analisar o multiculturalismo na educação infantil e suas implicações na sociedade e na formação de sujeitos capazes de superar os preconceitos e discriminações. Entre os documentos analisados estão os Indicadores de Qualidade na Educação Infantil e Diretrizes Curriculares Nacionais para a Educação Infantil (DCNEI). Com a finalidade de complementar as ideias apresentadas por estes documentos, citaremos, também, trabalhos científicos.

\section{O CONTEXTO DA EDUCAÇÃO INFANTIL}

A educação infantil trabalha com a formação de sujeitos capazes de atuarem na sociedade de maneira ativa e participativa.

Atendendo crianças de zero a cinco anos de idade, a educação infantil é responsável por criar oportunidades para que estas crianças tenham a possibilidade de experenciar, através do lúdico, situações que sejam capazes de formá-las, considerando as especificidades do mundo real. 
Neste contexto, o processo educacional assume um papel indispensável na formação de pessoas capazes de lutar contra os preconceitos, as discriminações e diversas outras formas de violência contra àqueles que possuem uma cultura diferente daquela estabelecida como padrão para a sociedade.

Albuquerque (2014) estabelece que:

A educação é de fato um motivo de discussão e preocupação da sociedade em geral. Afinal, o futuro da nação, ou melhor, do homem, enquanto ser humano, depende da humanização do indivíduo que se constrói através da educação. A aprendizagem do homem é um fenômeno natural, e, cada vez que socializamos as pessoas e as integramos na sociedade, elas se transformam e tornam-se mais aptas a promover a harmonia, a compreensão, a tolerância e a paz. (ALBUQUERQUE, 2014, p.11).

Nesta perspectiva, notamos que o processo de integração, extremamente presente na educação infantil, é uma experiência capaz de gerar uma sociedade mais tolerante em relação às diferenças, proporcionando conforme ressalta a autora, a formação de pessoas aptas a "promover a harmonia, a compreensão, a tolerância e a paz."

Os Parâmetros Nacionais de Qualidade para a Educação Infantil (2018) apontam a necessidade de trabalhar prioritariamente desde o início da escolarização as questões que envolvem a diversidade, a democracia e a inclusão, pois destacam que é nesta fase que as crianças constroem suas primeiras referências para estes valores.

Desta forma, é importante refletir sobre formação da criança, na educação infantil, dando enfoque a socialização e integração dos educandos com os adultos e com as outras crianças, como ações importantes na construção de um sujeito capaz de atitudes que valorizem a equidade e o respeito.

\section{MULTICULTURALISMO: OPORTUNIDADE OU OBSTÁCULO?}

As diferentes culturas estão presentes nas salas de aula e nas escolas desde a educação infantil e por todo o processo educacional. Tratar destas diferenças desde

RC: 104601

Disponível em:

https://www.nucleodoconhecimento.com.br/educacao/multiculturalismo-na-educacao 
os primeiros passos da criança em contato com o mundo são ações fundamentais e compõem os objetivos da educação infantil.

De acordo com o documento intitulado "Indicadores de Qualidade na Educação Infantil", temos que:

A instituição de Educação Infantil é habitada por um grupo de adultos e por um grupo de crianças. É, portanto, um espaço coletivo de convivência, onde acontecem interações entre crianças, entre crianças e adultos e entre adultos. Sendo uma instituição educacional, essas interações devem ser formadoras, no sentido de que devem ser baseadas nos valores sociais que fundamentam sua proposta pedagógica. A cidadania, a cooperação, o respeito às diferenças e o cuidado com o outro são aprendidos na vivência cotidiana. Por isso, não podemos esperar que as crianças desenvolvam essas atitudes se os adultos não as demonstram em sua forma de atuar na instituição, com as crianças, os colegas e as famílias. (BRASIL, 2009, p. 45).

Nesta perspectiva, notamos que o papel da escola na construção do respeito às diferentes culturas existentes, deve partir dos adultos presentes na instituição, sendo estes, exemplos para que as crianças aprendam a respeitar as diferenças e sejam capazes de atuar de maneira cooperativa, cuidando e respeitando aos outros. É no cotidiano da escola que a criança vivencia e desenvolve valores importantes para que seja capaz de atuar na sociedade, enxergando o outro como sujeito que carrega suas crenças, hábitos, valores e ideias próprias de suas culturas e convivências, que precisam ser respeitadas.

Ainda, o documento "Indicadores de Qualidade na Educação Infantil" (2009) destaca que os adultos devem fazer interferências sempre que necessário em situações de "racismo, de preconceito, agressões físicas e verbais entre crianças". Não obstante, devem ser valorizadas e incentivadas as expressões de amizade e cooperação.

O documento destaca ainda que, as rotinas usualmente realizadas no passado e de maneira rígida:

[...] representam um desrespeito ao direito e à dignidade das crianças. É preciso que os adultos estejam atentos para modificar aquelas práticas que tolhem as oportunidades de desenvolvimento infantil. Favorecer interações 
humanas positivas e enriquecedoras deve ser uma meta prioritária de toda instituição educacional. (BRASIL, 2009a, p. 43)

Diante disso, devem evitar castigos, gritos, situações humilhantes ou qualquer outro ato de violência que não seja capaz de construir momentos de diálogo, de acolhimento e de respeito às diversas formas de pensar e agir, presentes nas instituições de educação infantil.

De acordo com Moreira (2001), visando compreender melhor a multiculturalidade, esclarece que:

a multiculturalidade não se reduz a algo em que se acredite ou com o qual se concorde. Ela de fato existe, está entre nós e representa, neste fim de século, uma condição de vida nas sociedades ocidentais contemporâneas. Podemos ignorar ou abordar essa realidade de diferentes modos, mas não podemos apagá-la: ela permanece, independentemente de nossas respostas e de nossas reações. Ela estará sempre presente nos sistemas escolares, nas escolas, nas salas de aula, nas experiências da comunidade escolar, afetando inevitavelmente as ações e as interações de seus diferentes sujeitos. (MOREIRA, 2001, p.85)

Sendo assim, independente da nossa postura diante das diversas culturas existentes na escola, elas continuarão existindo, sendo causas de conflitos ou oportunidades de aprendizado.

Diante destes conflitos, o educador deve interferir, não podendo simplesmente ignorá-los. A reflexão de forma positiva sobre estes acontecimentos é essencial para que a criança tenha a oportunidade de entender que as suas ações são capazes de promover na sociedade, relações de harmonia ou discórdia, podendo resultar inclusive em violências físicas e psicológicas, se não forem identificadas e trabalhadas pelos educadores.

De acordo com as Diretrizes Curriculares Nacionais para a Educação Infantil (DCNEI), esta fase do processo educacional assume um importante papel na formação das crianças, de maneira que esse multiculturalismo seja respeitado, através de experiências de forma positiva em relação aos diferentes povos. 
Desde muito pequenas, as crianças devem ser mediadas na construção de uma visão de mundo e de conhecimento como elementos plurais, formar atitudes de solidariedade e aprender a identificar e combater preconceitos que incidem sobre as diferentes formas dos seres humanos se constituírem enquanto pessoas. [...] É necessário criar condições para o estabelecimento de uma relação positiva e uma apropriação das contribuições históricoculturais dos povos indígenas, afrodescendentes, asiáticos, europeus e de outros países da América, reconhecendo, valorizando, respeitando e possibilitando o contato das crianças com as histórias e as culturas desses povos. (BRASIL, 2009, p. 89).

Desta forma, desde muito cedo a criança deve ser encaminhada a reconhecer as diferenças existentes na sociedade, buscando não só tratar com respeito àqueles que agem e pensam de forma diferente, mas também engajando em lutas que visem à promoção da solidariedade, do acolhimento e ao combate às diferentes formas de preconceitos e discriminações.

É preciso que a escola não se silencie diante das diversas culturas que a envolve. De acordo com Moreira e Candau (2003) a escola, diante das dificuldades em lidar com as diferenças e pluralidades, tende a neutralizá-las ou silenciá-las, buscando a homogeneização e padronização. No entanto, é necessário que a escola aceite o desafio de abrir espaços para as diferenças e os cruzamentos culturais.

Não podemos conceber uma escola que não reconheça as diversidades culturais existentes em sua constituição, pois ações como estas inviabilizam os objetivos do processo educacional e, em especial, na educação infantil, não viabilizam a formação de uma criança constituída de valores históricos e culturais, sendo capaz de tomar decisões e agir de forma ativa na transformação da sociedade, em busca da equidade para todos, independente da raça, cor, sexo, religião, entre outros.

Forquin (2000) destaca que:

um ensino pode estar endereçado a um público culturalmente plural sem ser, ele mesmo, multicultural. Ele só se torna multicultural quando desenvolve certas escolhas pedagógicas que são, ao mesmo tempo, escolhas éticas ou políticas. Isto é, se na escolha dos conteúdos, dos métodos e dos modos de organização do ensino, levar em conta a diversidade dos pertencimentos e das referências culturais dos grupos de alunos a que se dirige, rompendo com o etnocentrismo explícito ou implícito que está subentendido historicamente

RC: 104601

Disponível em:

https://www.nucleodoconhecimento.com.br/educacao/multiculturalismo-na-educacao 
nas políticas escolares "assimilacionistas", discriminatórias e excludentes (FORQUIN, 2000, p.61)

O autor retoma a necessidade de que o multiculturalismo seja considerado pela escola, como fator determinante na elaboração do ensino e construção do conhecimento. Somente através de um trabalho pedagógico, que considere e interaja com os diferentes grupos culturais que estão presentes na escola, é possível passar de uma pedagogia de transmissão, que aumenta a exclusão, para uma pedagogia participativa capaz de acolher o educando e criar condições para que este tenha a oportunidade de protagonizar suas ações no mundo.

Neste sentido, notamos que o papel do educador ganha um novo significado, desde que as questões culturais estejam presentes no preparo de seu trabalho docente.

Candau (2008) cita:

O/a educador/a tem um papel de mediador na construção de relações interculturais positivas, o que não elimina a existência de conflitos. O desafio está em promover situações em que seja possível o reconhecimento entre os diferentes exercícios em que promovamos o colocar-se no ponto de vista, no lugar sociocultural do outro, nem que seja minimamente, descentrar nossas visões e estilos de afrontar as situações como os melhores, os verdadeiros, os autênticos, os únicos válidos. Para isto é necessário promover processo sistemáticos de interação com os "outros", sem caricaturas, nem estereótipos. Trata-se também de favorecer que nos situemos como "outros", os diferentes, sendo capazes de analisar nossos sentimentos e impressões. (CANDAU, 2008, p. 31,32)

Diante desta perspectiva, podemos notar que a educação infantil é o momento propício para se trabalhar com as questões interculturais, uma vez que nela o processo de interação torna-se constante em suas atividades, bem como o ato de se colocar, ainda que minimamente, no lugar do outro, possa ser construído de maneira lúdica e eficiente.

Importante considerar ainda, que a criança, público-alvo da educação infantil, está iniciando seu processo de formação enquanto sujeito atuante na sociedade, e embora traga conteúdos culturais oriundos de seu ambiente familiar e de convivência, é possível propor uma transformação, de maneira que esta criança seja 
capaz de repensar suas atitudes e criar formas de agir e pensar diante de situações que envolvam diferenças culturais que sejam geradoras de conflitos.

Para que tenhamos a capacidade de promover uma educação intercultural, é necessário superarmos o "daltonismo cultural", expressão utilizada por Stephen Stoer e Luiza Cortesão (1999):

Ao apontar o multiculturalismo como uma nova forma de globalização, Boaventura Sousa Santos afirma que o mundo é um "arco- -íris de culturas" (Santos, 1995). Ora, partindo deste conceito para uma (eventualmente arriscada) analogia, e admitindo que é importante ser capaz de 'ver' este e outros conjuntos de cores, poderemos recordar que algumas pessoas, apesar de disporem de um aparelho visual morfologicamente bem constituído, não são capazes de discernir toda uma gama de tonalidades que compõem o arco-íris. Alguns ficam com uma capacidade reduzida de identificação de tons cinzentos: são os daltônicos. A analogia proposta aqui é a de que a não conscientização da diversidade cultural que nos rodeia em múltiplas situações, constituiria uma espécie de "daltonismo cultural" (STOER; CORTESÂO, 1999, p.56)

Desta maneira, Candau (2008) acrescenta:

Ter presente o 'arco-íris das culturas' nas práticas educativas supõe todo um processo de desconstrução de práticas naturalizadas e enraizadas no trabalho docente para sermos educadores/as capazes de criar novas maneiras de situar-nos e intervir no dia a dia de nossas escolas e salas de aula. (CANDAU, 2008, p. 28)

Sendo assim, é possível compreender que o multiculturalismo existente na escola não é apenas um gerador de conflitos, que finalize em atos de preconceitos, discriminações e exclusões, mas tem a possibilidade de, através de intervenções por parte dos educadores, ser um trabalho que envolve o reconhecimento de si e do outro como sujeitos únicos, constituídos de histórias e culturas, que proporcionem um ambiente rico de aprendizagens capazes de promover a tolerância, a empatia e a construção de um mundo justo e acolhedor.

\section{CONSIDERAÇÕES FINAIS}

Para que a educação não seja uma ferramenta de exclusão é necessária uma reflexão acerca da diversidade que ela deve atender. São necessárias as 
elaborações de políticas públicas e ações concretas que visem a diminuição das diferenças criadas por uma sociedade baseada em uma cultura dominante, que privilegia àqueles com maiores poderes aquisitivos e sociais.

Diante disso, para que as diferenças entre hábitos, pensamentos e ações sejam oportunidades de aprendizagens e não obstáculos, é necessário que a educação infantil oportunize o trabalho com as diferenças, de maneira lúdica, para que as crianças compreendam a importância de se colocar no lugar do outro e percebam que as pessoas são diferentes, mas que essas diferenças devem ser acolhidas e respeitadas.

As crianças devem ser encaminhadas às relações positivas com àqueles que tem formas diferentes de agir e pensar, reconhecendo estas diferenças e entrando em contato com elas de forma dialógica e efetivamente satisfatórias.

O educador como mediador deste processo, deve aproveitar as oportunidades, inclusive os conflitos, para levarem as crianças a vivenciarem sentimentos de solidariedade, tolerância, respeito, acolhimento e harmonia, garantindo desta forma a possibilidade de uma transformação social, desde o início do processo educacional.

\section{REFERÊNCIAS}

ALBUQUERQUE, Rosangela Nieto. A escola e o Futuro: Alunos Gerações x,y,z... Que Alunos Vamos Deixar para o Mundo? Rev. Construir Notícias, Recife, №. 75, Ano 13, Mar./abr. 2014. Disponível em: htpps://www.construirnoticias.com.br/aescola-e-o-futuro-alunos-geracoes-x-y-z-que-alunos-vamos-deixarpara-o-mundo/. Acesso em: 15/07/2021.

BARBOSA, Ana Clarisse Alencar. Sociedade democrática: entre a identidade e a diversidade. Londrina: S.A, 2014. p. 03-33. 
BRASIL. Diretrizes curriculares nacionais para a educação infantil /Secretaria de Educação Básica. - Brasília, DF: MEC, SEB, 2010.

BRASIL. Indicadores da qualidade na Educação Infantil. Brasília, DF: MEC, 2009.

BRASIL. Parâmetros Nacionais de qualidade da Educação Infantil. Brasília, DF: MEC, 2018.

CANDAU, Vera Maria Ferrão. Multiculturalismo e educação: desafios para a prática pedagógica. In: MOREIRA, Antonio Flávio \& CANDAU, Vera Maria Ferrão (org.). Multiculturalismo: diferenças culturais e práticas pedagógicas. 2. ed. Petrópolis, Rio de Janeiro: Vozes, 2008.

FORQUIN, Jean Claude. O currículo: entre o relativismo e o universalismo. Educação e Sociedade, v.21, ํo 73, 2000. Disponível em: https://www.scielo.br/j/es/a/njxtpj9s6CdQHVd4wyyRKYS/?lang=pt\&format=pdf. Acesso em: 15/07/2021.

MOREIRA, Antonio Flávio Barbosa. Currículo: Políticas e Práticas. Campinas: Papirus, 2001.

MOREIRA, Anatonio Flávio \& CANDAU, Vera Maria Ferrão. Educação escolar e cultura(s): construindo caminhos. Revista Brasileira de Educação, n.23, p.156 168, mai.-ago, 2003.2 Disponível em: https://www.scielo.br/j/rbedu/a/99YrW4ny4PzcYnSpVPvQMYk/?lang=pt\&format=pdf. Acesso em 10/07/2021.

PNUD - Programa das Nações Unidas para o Desenvolvimento. Relatório do desenvolvimento humano 2004: liberdade cultural num mundo diversificado. Lisboa: Mensagem, 2004. 
STOER, Stephen; CORTESÃO, Luisa. "Levantando a pedra": da pedagogia inter/multicultural às políticas educativas numa época de transnacionalização. Porto: Afrontamento, 1999.

Enviado: Setembro, 2021.

Aprovado: Janeiro, 2022. 